\title{
Investigating the Role of Attentional Bias or Selective Information Processing and Focus of Attention in Children with Conduct Disorder and Normal Children
}

\author{
Beheshtian Elahe \\ M.A. in Clinical Psychology, Department of Psychology, Faculty of Humanities, Neyshabur Branch, \\ Islamic Azad University, Neyshabur, Iran \\ Toozandehjani Hassan* \\ Assistant Professor, Ph. D. of Psychology, Department of Psychology, Faculty of Humanities, Neyshabur Branch, \\ Islamic Azad University, Neyshabur, Iran \\ ${ }^{*}$ Corresponding Author Email: H. Toozandehjani@ymail.com
}

\author{
Doi:10.5901/mjss.2016.v7n3s3p143
}

\section{Abstract}

This research is a quasi-experimental and causal-comparative study, which has been conducted to compare the attentional bias or selective information processing and focus of attention in children with conduct disorder and normal children. Out of the children referring to psychiatric offices and Psychological Services Center in Neishabour, 50 children with conduct disorder (according to diagnostic interview based on DSM-IV and interview using KSADS) were selected through voluntary and available sampling. Normal sample was selected through multistage cluster sampling from among the school students of Neishabour City. Questionnaires on attentional bias, Stroop Test and Recognition test were applied for data collection. Data was analyzed in independent groups using t-test. The results indicated that there is a significant difference between children with conduct disorder and normal children in terms of attentional bias or selective information processing and focus of attention $(p<0.05)$.

Keywords: Attentional bias, selective information processing, focus of attention, conduct disorder

\section{Introduction}

Conduct disorder is among the complex disorders since it revolves around fear of unobservable events such as negative evaluation, criticism or rejection by others (Houghton \& Salkovix, 1997; cited in Qasemzadeh, 1997). According to available reports, lifetime prevalence of conduct disorder is 3 to $13 \%$. This shows that conduct disorder is a common disorder and a lot of people are faced with this problem. With the increasing interest in conduct disorder in recent years, a strong need is felt to achieve methods for accurate assessment and treatment of this disorder (Khadivizand, 2006). In a study, $7.6 \%$ of children and $3.7 \%$ of adolescents met the criteria for conduct disorder (Workman \& Katz, 2004; cited in Mohammad Esmaeil, 2004). Conduct disorder during childhood and adolescence is accompanied by serious problems in the functioning of individuals and evidence shows that the prevalence of this disorder is increasing (Heimberg \& Barlow, 1991).

Some believe that conduct disorder in many children with this disorder is not diagnosed until it leads to school refusal or disruptive behaviors in school (Beadle \& Morris, 1995). This disorder starts relatively early so that some young children are diagnosed to suffer from this disorder (Beidel, Turner\& Morris, 1998).

Most of the children with conduct disorder cannot remember at what stage of their life they were affected by this disorder. Moreover, conduct disorder in adolescents is connected with depression (Heimberg et al., 2001). Some researchers have found that children whose primary diagnosis is generalized anxiety disorder have a secondary diagnosis associated with conduct disorder (Albano et al., 1995; Beidel, 1991; Strauss, 1988). The symptoms of many children with generalized anxiety disorder gradually decrease (Laset, Puriyn, Herson \& Kadin, 1996; cited in Komijani, 2005).

Conduct disorder is one of the most common disorders in childhood and is among the main reasons for referral to health centers (Burke \& Pardini; cited in Pour Afkari, 1991). This stable conduct disorder is characterized by aggression and violation of the rights of others (Kaplan \&Sadok, 1998; cited in Pour Afkari, 1991). The main symptom of conduct disorder in DSM-V is repeated and continuous pattern of behavior in which fundamental rights of others and basic social 
norms or standards are violated commensurate with the age of the person. These behaviors fall into four main groups: Aggressive behavior that causes threat or physical or emotional harm to other individuals or animals; non-aggressive behavior which causes financial damage; fraud or theft, and serious violations of the rules that existed within 6 months. The second diagnostic symptom of conduct disorder in DSM-V is that these behaviors clinically cause significant impairment in social, academic or occupational functioning. The third symptom is that if the person is 18 years old or older, criteria do not match with antisocial personality disorder. Two types of childhood (before 10 years old) and adolescence (after 18 years old) have been identified (cited in Nourbala et al., 1995).

Conduct disorders in ICD-10 with a repetitive and persistent pattern of anti-social behavior include aggression or indifference. Conduct disorder is frequently associated with maladaptive psychosocial environments (such as disturbed family environment) and occurs more often in boys. The symptoms of this disorder should persist for at least 6 months (Toozandehjani, 1996).

This pattern of behavior is accompanied by emotional and social turmoil (House, 1999), aggressive and coercive behavior towards parents and teachers (Gary, 2002), poor academic performance (Meadows et al., 1994), low selfesteem (Salimi \& Calias, 1996) and impaired social and non-verbal skills (Mathur et al., 1992) and reveals a complex image of conduct disorder. Delinquent behavior of adolescents with conduct disorder is caused by their inadequate social learning experience; that is, previous environment of these adolescents have not provided necessary training, paradigms and feedbacks for learning appropriate behaviors. So, lack of proper behavior makes adolescents rely on their deviant peers and such people provide them with training and patterns which develop behavioral problems (Kazdin et al., 1992; cited in EbrahimiMogaddam, 2012).

The results of studies indicate that the major challenges for adolescents with conduct disorder include having communication with others, compliance with social norms and aggression control (Derry et al., 1999). Behavioral patterns of adolescents with conduct disorder, such as aggressive and coercive behavior towards parents and teachers, poor academic performance, low self-esteem, weakness in social skills and interpersonal interaction and inability to deal with the problem, are caused by inadequate social learning experience (Marx et al., 2008). Environment has not provided these adolescents with necessary training, paradigms and feedbacks for learning appropriate behaviors. Dysfunctional family environment particularly marital discord is effective in the incidence and persistence of conduct disorder in adolescents (Anent \& Reguram, 2005). Findings suggest that children with conduct disorder distort or misinterpret social cues during social interactions with others. For example, a neutral position may be taken as a hostile situation.

Cognitive patterns of conduct disorders are based on the idea that cognitive factors play an important role in the etiology and persistence of conduct disorder. In recent years, considerable emphasis has been placed on information processing patterns, that is, the way people perceive environmental stimuli and it is believed that "bias" in the processing of emotional information underlies conduct and anxiety disorders and this bias exists in all stages of information processing, namely attention, interpretation and memory (Beck \&Clark, 1997; Beck et al., 1985; Mathews \& Macleod, 1994; cited in Ostovar, 2006).

According to the theory of involuntary and autonomous repetition, most of behavioral, emotional and cognitive characteristics result from high levels of self-concentration, which is due to the inability of individuals with self- focused attention in getting out of the autonomous cycle following the loss of the main source of self-esteem (Mobini, 2003).

Self- focused attention is applied to increased personal awareness of inner perceptual events, knowledge of motor actions in the past and present, knowledge of the more or less permanent data of the mind such as personal attitudes and temporary information of the mind, and external-focused attention refers to increased individual awareness of thoughts, feelings and behavior of another person through the processing of the information referring to others (Mobini, 2003). Self-focused attention is an awareness of information and references related to a person, which has been internalized and is placed against external information that is received through sensory receptors (Inglhart, 1990). Selffocused attention includes knowledge of physical condition, feelings, thoughts, emotions and memories. Self-focused attention is a common process to all psychological disorders (Inglhart, 1990) particularly when it is too continuous and constant. Woodruff-Martin et al. (2001) found that self-report tendency toward self-focused attention is common to panic disorders, depression and other social anxiety disorders, and that self-focused attention greatly increases the psychological trauma (Branch \& Wilson; cited in QaracheDaqi, 2012).

Selective attention is associated with the process through which special stimuli in the internal and external environment are selected for further processing. Selective attention is related to the initial screening of the stimulus rather than its continuation (Martin, 2008). More importantly, both controlled and automatic processes have a common place in human information processing system (Blackburn \& Davidson; cited in Toozandehjani, 2008). Cognitive biases show that all information is not processed equivalently and in the same way (Rasti, 2006).

Individuals' perception of threat is explained by their mental judgment about "the possibility" of the occurrence of a 
negative event and "intensity" or "hatred" of that event. Expectation of a negative or harmful event means that anxiety is called by the perceived threat (Beck, Emery \& Greenberg, 1985) in people with conduct disorder (Karen et al., 2009). So, individuals with conduct disorder estimate the likelihood and severity of occurrence of negative events as higher compared to normal people. Over the past few decades, several theoretical models have been presented to explain the mechanisms underlying conduct disorder, some of which emphasize cognitive processes (e.g., Beck, Emery \& Greenberg, 1985; Wells, 1995). Although it is likely that such exaggerating judgments are associated with most levels of emotional disorders, several theorists believe that subjective judgments are specific to any anxiety disorder. Therefore, radical estimate of the probability and severity of the occurrence of negative social events is specific to conduct disorder (Beck et al., 1985; Foa \& Kozak, 1985; cited in Ostovar, 2006).

Thus, given that little research has been done in our country on focus of attention and selective information processing or selective attention in children with conduct disorder, performing the present study seems essential in order to better understand cognitive biases, focus of attention, selective information processing and persistence of conduct disorder in these children.

\section{Materials and methods}

This research is a quasi-experimental and causal-comparative study, which has been conducted in 2014 to examine the role of attentional bias or selective attention and focus of attention in children with conduct disorder and normal children in Neishabour. Statistical population of the research consists of all the children with conduct disorder who referred to private psychiatric clinics and Psychological Services Center in Neishabour City during the last quarter of 2014. Also, population of normal people includes all elementary school children in Neishabour. The research sample consists of 50 children (8 to 12 years) with conduct disorder, who were selected from among the children of the statistical population (based on the diagnostic interview using KSADS method), through voluntary and available sampling. In addition, 50 normal children were selected from among primary school students of Neishabour, through multistage cluster sampling.

In this study, Emotional Stroop and focus of attention questionnaire (FAQ) were used for data collection.

Semi-structured clinical interview: This interview has been set based on Diagnostic and Statistical Manual of Mental Disorders (Fifth Edition) by American Psychiatric Association, which provides the reliability and validity of a clinical interview in addition to facilitate the process of assessment and identification of resources. In these interviews, questions are closed (Haqiqi, 2012). Besides, one of the goals of the creators of this tool was to design the interviews that, while being structured, are easy to be used by clinical experts (Spitzer \&Williams, 1992; cited in Haqiqi, 2012). Semi-structured clinical interview has been developed base on nearly 400 empirical studies and research topics. In the research conducted by Pasha Sharifi et al. (2008), which aims to assess the reliability and applicability of this interview, the first stage dealt with translation of the tool and investigation of inter-cultural validity and in the second stage, reliability and applicability of Persian translation in clinical population of Iran were studied. The results showed the acceptable reliability of diagnoses with Persian version and its optimal applicability, which indicate the ability to use this tool in making research, educational and clinical diagnoses.

Strength and difficulties questionnaire (SDQ): This questionnaire was designed in 1997 in England, based on the diagnostic criteria of the 10th revision of the International Statistical Classification of Diseases and Related Health Problems and is used for ages 3 to 16 years (Goodman, 1997). It has five subscales which include emotional symptoms, conduct problems, attention deficit hyperactivity, problem in relationship with peers and pro-social behaviors (children's strengths). Among the advantages of this questionnaire are its shortness, comprehensiveness, good reliability and diagnostic power despite shortness, existence of four similar self-assessment forms of teacher and parents, its translation into forty languages of the world, easy application, giving grades to the strengths of children and adolescents, in addition to behavioral problems, matching the subscales of its materials with International Classification of Diseases (ICD-10) and using the same materials in almost all the articles of the four forms (cited in Haqiqi, 2012).

In the research by Flitlich-Bilk (2004), correlation of double implementation of parent form in SDQ questionnaire with the average interval of 19 days was equal to 0.79 . Overall reliability of teacher form in the study by Becker et al. (2000) was 0.82 and the reliability of its subscales was reported between 0.75 and 0.87 . Shah Moradi (2006) implemented the two forms of teacher and parents and reported the reliability of 0.42 for the parents form and reliability of 0.36 for the teacher form, using Cronbach's alpha. In the research conducted by Mohammadi (2006), overall reliability obtained for the self-report form was reported 0.67 , using Cronbach's alpha. Also, the reliability for its subscales including emotional symptoms, conduct problems, attention deficit hyperactivity, problem in relationship with peers and children's strengths (pro-social behaviors) was obtained respectively 0.56, 0.38, 0.49, 0.34 and 0.50 (cited in Haqiqi, 2012).

Focus of attention questionnaire (FAQ): It is a 10-item questionnaire. Self-report measures are designed to 
assess the extent to which a person focused on internal or external stimuli during the previous social interaction. Items are graded on a five-point Likert scale ( $1=$ not at all and $5=$ completely). Higher scores in $\mathrm{FAQ}_{\text {self indicate that more }}$ attention was devoted to internal stimuli while higher scores in $\mathrm{FAQ}_{\text {external }}$ show that more attention was allocated to external stimuli. In adults FAQ, internal consistencies of 0.76 and 0.72 were obtained respectively for self-focus and external focus, and it showed the manipulations of self-focus and treatment for social phobia. This questionnaire includes two five-item subscales including Self-Focus Questionnaire and External Focus Questionnaire. Woody et al. (1997) obtained Cronbach's alpha coefficients of 0.76 and 0.72 respectively for the subscales of Self-Focus Questionnaire and External Focus Questionnaire. Mellings and Alden (2000) also reported Cronbach's alpha coefficients of 0.87 and 0.49 respectively for the subscales of self-focus and external focus. Woody et al. (1997) investigated the construct validity of this scale using Principal Components Analysis and two-factor structure of the questionnaire was confirmed. Jalali (2007) reported the construct validity of 55.85 for the questionnaire, using Principal Components Analysis and varimax rotation. In addition, he obtained Cronbach's alpha coefficients of 0.75 and 0.86 respectively for the subscales of self-focus and external focus. Cronbach'salpha coefficients for the subscales of Self-Focus Questionnaire and External Focus Questionnaire were respectively 0.84 and 0.86 .

Emotional Stroop Test: It was designed for the first time by Ridley Stroop in 1935 in order to measure the selective attention and cognitive flexibility. This test has been used in various studies and for numerous clinical groups to measure the ability of response inhibition, selective attention, cognitive variability and cognitive flexibility. The test applied consists of two steps as follows: First step: naming colors; in this step, the subjects were asked to specify the color of the intended shape in a colorful set (e.g., they should determine the color of the circle which has been shown in four colors of red, blue, yellow and green). The aim of this step is only practice and identification of colors and place of buttons on the keyboard and it has no effect on the final result.

Second step: it includes the main implementation of Stroop test. In this step, 48 consonant colorful words and 48 inconsonant colorful words are displayed in the colors of red, blue, yellow and green. In total, 96 consonant and inconsonant colorful words are shown randomly and sequentially. The subjects are required to determine the apparent color of the words, regardless of their meaning. The time of stimulus presentation on the screen is 2 seconds and the interval between the presentations of two stimuli is 800 milliseconds. Scholars believe that color-word task (second stage of experiment) measures mental flexibility, interference and response inhibition. The amount of interference is obtained by subtracting the score of inconsonant correct number from the score of consonant correct number. Research conducted on this test suggests its appropriate reliability and validity for inhibition measurement in adults and children. Validity of this test has been reported within the range of 0.80 and 0.91 , using retesting (cited in MacClaude et al., 2000).

Recognition test: To provide recognition test, sixteen symptoms of physical threat, sixteen symptoms of social threat, sixteen symptoms of threat of generalized anxiety disorder and social phobia and sixteen positive symptoms were selected for each of the groups. None of these symptoms had not been applied in Stroop test (main test), but in terms of content, they were similar to the symptoms that were used in the main test. The entire four groups of recent symptoms and a total of four groups of symptoms used in the main test were added together (128 symptoms) and were scattered randomly over a separate paper. Brief instructions for this section were prepared.

To describe the demographic characteristics of subjects, descriptive statistics indicators (mean, standard deviation and histogram) were employed. Also, inferential statistics indices (such as Kolmogorov-Smirnov test, t-test for independent groups, Mann-Whitney test) were used for data analysis.

\section{Research findings}

Table 1: Descriptive statistics for the group with conduct disorder

\begin{tabular}{lcccccc}
\hline Variables & Number & Variation range & Mean & Standard deviation & Skewness & Prominence \\
\hline Self-focused attention & 50 & 17 & 16.04 & 4.61 & -0.29 & -0.609 \\
\hline External-focused attention & 50 & 13 & 13.22 & 3.43 & -0.599 & -0.589 \\
\hline Attentional bias & 50 & 28 & 16.12 & 6.65 & -0.002 & -0.342 \\
\hline Negative affect & 50 & 23 & 24.89 & 6.48 & -0.329 & -0.946 \\
\hline Positive affect & 50 & 32 & 32.56 & 8.18 & -0.428 & -0.112 \\
\hline
\end{tabular}


Table 2: Kolmogorov-Smirnov test for conduct disorder

\begin{tabular}{llllll}
\hline & Self-focused attention & External-focused attention & Attentional bias & Negative affect & Positive affect \\
\hline Kolmogorov-Smirnov Z statistic & 0.56 & 1.78 & 0.595 & 0.741 & 0.823 \\
\hline P-value & 0.913 & 0.003 & 0.871 & 0.643 & 0.507 \\
\hline
\end{tabular}

The results of Table 2 show that level of significance in the research variables is higher than 0.05 . So, null hypothesis in Kolmogorov-Smirnov test,indicating the normality of observations for the cases mentioned in conduct disorder, is accepted ( $p>0.05$ ). In the above table, Kolmogorov-Smirnov test statistic for the variable of external-focused attention is less than the amount of standard normal table. Thus, normality hypothesis in this case is not confirmed. Accordingly, we cannot use classic tests to make a comparison between children with conduct disorder and normal children. In fact, nonparametric tests should be applied in this case to compare the groups.

Table 3: Kolmogorov-Smirnov test for normal children

\begin{tabular}{lccccc}
\hline & Self-focused attention & External-focused attention & Attentional bias & Negative affect & Positive affect \\
\hline Kolmogorov-Smirnov Z statistic & 0.612 & 1.776 & 0.712 & 0.839 & 0.679 \\
\hline P-value & 0.848 & 0.004 & 0.692 & 0.482 & 0.746 \\
\hline
\end{tabular}

Given that the significance level is more than 0.05 for all variables except for external-focused attention, normality hypothesis for self-focused attention, attentional bias, negative affect and positive affect is accepted. Regarding the variable of external-focused attention, normality hypothesis is rejected. Therefore, nonparametric tests such as Wilcoxon have been used to compare the observations in normal children and children with conduct disorder.

Table 4: Summary of t-test results for the scores of focus of attention questionnaire (self-focused attention)

\begin{tabular}{|c|c|c|c|c|c|c|c|}
\hline \multirow{3}{*}{$\begin{array}{l}\text { First hypothesis, } \\
\text { Self-foused attention }\end{array}$} & \multicolumn{3}{|c|}{ Levene test for equality of variance } & \multicolumn{4}{|c|}{ T-test for testing the equality of means } \\
\hline & \multirow[t]{2}{*}{ F statistic } & \multirow[t]{2}{*}{$P$ value } & \multirow{2}{*}{$\begin{array}{c}\mathrm{T} \\
\text { statistic }\end{array}$} & \multirow{2}{*}{$\begin{array}{l}\text { Degrees of } \\
\text { freedom }\end{array}$} & \multirow{2}{*}{$\begin{array}{c}P \\
\text { value }\end{array}$} & \multicolumn{2}{|c|}{$\begin{array}{l}\text { 95\% confidence interval for } \\
\text { differences }\end{array}$} \\
\hline & & & & & & Minimum & Maximum \\
\hline $\begin{array}{l}\text { Accepting the equality of } \\
\text { variance hypothesis }\end{array}$ & \multirow{2}{*}{6.72} & \multirow{2}{*}{0.012} & -2.73 & 98 & 0.008 & -3.73 & -0.605 \\
\hline $\begin{array}{l}\text { Rejecting the equality of } \\
\text { variance hypothesis }\end{array}$ & & & -2.73 & 86.25 & 0.008 & -3.73 & -0.602 \\
\hline
\end{tabular}

The results of the above table suggest that the equality of variances hypothesis is rejected through Levene test. In other words, the amount of Fisher statistic $(F=6.72)$ is higher than the corresponding value in Fisher Table ( $F=3.93)$. Accordingly, the null hypothesis indicating the equality of variances of two samples is rejected. Since the absolute value of $t$-statistic calculated $(t=-2.73)$ in this Table is more than its corresponding value in $t$-student Table $(t=1.98)$, it is concluded with the probability of $95 \%$ that there is a significant difference between the studied variables. According to the data collected and considering the significance of the null hypothesis, researcher's hypothesis indicating that "selffocused attention in the group with conduct disorder is more than the normal group" is accepted.

Table 5: Summary of Mann-Whitney test results to compare the two groups using nonparametric method

\begin{tabular}{|l|c|l|c|c|}
\hline & Average of ratings & Statistic & Test statistic value & Level of significance \\
\hline Normal children & 59.17 & Mann-Whitney statistic & 816.5 & \multirow{2}{*}{0.003} \\
\cline { 1 - 3 } Conduct disorder & 41.83 & Wilcoxon statistic & 2091.5 & \multirow{2}{*}{-3.004} \\
\cline { 1 - 3 }
\end{tabular}

According to the results of the above table, the statistic calculated for comparing the normal children and children with conduct disorder using nonparametric method $(Z=-3.004)$ is more than its corresponding statistic in the standard table $(Z=1.96)$. Therefore, it is concluded with the probability of $95 \%$ that there is a significant difference between the studied variables. According to the data collected and considering the significance of the null hypothesis, researcher's hypothesis indicating that "external-focused attention in children with conduct disorder is less than the normal children" is accepted. 
Table 6: T-test for comparing the two independent samples of selective attention

\begin{tabular}{lccccccc}
\hline \multirow{2}{*}{$\begin{array}{l}\text { Third hypothesis, } \\
\text { Attentional bias }\end{array}$} & Levene test for equality of variance & \multicolumn{3}{c}{ T-test for testing the equality of means } \\
\cline { 2 - 7 } & F statistic & P value & $\begin{array}{c}\mathrm{T} \\
\text { statistic }\end{array}$ & $\begin{array}{c}\text { Degrees of } \\
\text { freedom }\end{array}$ & $\begin{array}{c}\mathrm{P} \\
\text { value }\end{array}$ & $\begin{array}{c}95 \% \text { confidence interval for } \\
\text { differences }\end{array}$ \\
\hline $\begin{array}{l}\text { Accepting the equality of } \\
\text { variance hypothesis }\end{array}$ & 3.75 & 0.052 & -3.91 & 98 & 0.00 & -7.17 & -2.33 \\
\hline $\begin{array}{l}\text { Rejecting the equality of } \\
\text { variance hypothesis }\end{array}$ & & & -3.91 & 92.64 & 0.00 & -7.17 & -2.34 \\
\hline
\end{tabular}

The results of the above table show that the equality of variances hypothesis is accepted through Levene test statistic. In other words, the amount of Fisher statistic $(F=3.75)$ is less than the corresponding value in Fisher Table $(F=3.93)$. Accordingly, the null hypothesis indicating the equality of variances of two samples is accepted. Since the absolute value of $t$-statistic calculated $(t=-3.93)$ in this Table is more than its corresponding value in $t$-student Table $(t=1.98)$, it is concluded with the probability of $95 \%$ that there is a significant difference between the studied variables. According to the data collected and given the significance of the null hypothesis, researcher's hypothesis indicating that "attentional bias in children with conduct disorder is more than the normal children" is accepted.

Table 7: Comparing the two groups in terms of self-focused attention and external-focused attention

\begin{tabular}{|c|c|c|c|c|c|c|}
\hline & $\begin{array}{l}\text { Estimation of } \\
\text { coefficients }\end{array}$ & $\begin{array}{l}\text { Standard } \\
\text { deviation }\end{array}$ & $\begin{array}{c}\text { Wald } \\
\text { estimation }\end{array}$ & $\begin{array}{l}\text { Degrees of } \\
\text { freedom }\end{array}$ & $\begin{array}{c}\text { Level of } \\
\text { significance }\end{array}$ & $\begin{array}{c}\text { EXP } \\
\text { coefficients }\end{array}$ \\
\hline Constant coefficient & 1.43 & 2.207 & 0.430 & 1 & 0.509 & 0.232 \\
\hline Self-focused attention & 0.149 & 0.064 & 5.473 & 1 & 0.017 & 1.165 \\
\hline $\begin{array}{l}\text { External-focused } \\
\text { attention }\end{array}$ & -0.225 & 0.082 & 7.267 & 1 & 0.005 & 0.795 \\
\hline Attentional bias & 0.084 & 0.045 & 3.344 & 1 & 0.045 & 1.087 \\
\hline Negative affect & 0.084 & 0.040 & 4.189 & 1 & 0.039 & 1.07 \\
\hline Positive affect & -0.016 & 0.034 & 0.254 & 1 & 0.611 & 0.980 \\
\hline
\end{tabular}

Thus, only positive affect has no significant effect on children's condition. Generally, the research results showed that self-focused attention in children with conduct disorder is more than normal children. On the other hand, external-focused attention in children with conduct disorder is less than normal children. Also, it was found that attentional bias and negative affect in children with conduct disorder are more than normal children and positive affect in children with conduct disorder and normal children has no significant difference.

\section{Discussion and Conclusion}

This study was conducted in order to compare the focus of attention and attentional bias or selective attention in children with conduct disorder and normal children. The first hypothesis stated that "self-focused attention in children with conduct disorder is different from normal children". As mentioned previously, the results indicated that attentional bias and focus of attention have significant differences in children with conduct disorder and normal children. It means that the greater the conduct disorder in children, the more the self-focus of attention and interference in selective attention will be. Moreover, these findings are consistent with the results obtained by Houghton et al., (2002), Beck, Emery and Greenberg (1985), Kar (1974), Mobini (2003) and Inglhart (1990) regarding self-focus of attention and negative self-assessment of one's performance in conduct disorder. In addition, these studies are congruent with the studies that have shown a relationship between conduct disorder with biased interpretation of social situations and ambiguous situations (Kurpita, Albano \& Barlow, 1996). Based on studies, individuals suffering from conduct disorder also show interpretation bias in ambiguous situations (Williams, Watts \& Macleod, 1988; cited in Mobini, 2003).

The second research hypothesis suggested that "external-focused attention in children with conduct disorder is less than normal children". This result is consistent with the findings by Blarney (1986), indicating that children suffering from panic disorder worry that others consider them a fool. According to Long (1979), conduct disorder is defined as an uncomfortable experience in the presence of others (Vleeming \& Engels, 1981; cited in Albano, 1995). Irrational and individual behaviors are recognized as the fear of being judged in social situations. Individuals with conduct disorder 
consider many of the negative problems of life as the result of their own disruptive behavior (Heimberg, 1991). Children suffering from conduct disorder have a high score in general sensitivity (Buss, 1980, cited in Jalali, 2007).

One-third of children with conduct disorder also suffer from depressive disorder (Mojtahedi et al., 2006). Smith et al. (2009) found that children with conduct disorder watch out for evaluative signs and clues. Fears of parents of children with conduct disorder are significantly concerned with their disruptive behaviors which include the unnecessary concern about the opinions of others (Brach and Heimberg, 1994). Spence (1999; cited in Beidel, Turner \& Morris, 1999) found that Adolescents with conduct disorder have significantly more anxiety and show poor social functioning in the assessment of behavioral tasks. Walters and Inderbitzin (1988) demonstrated that obedient children have more destructive behavior than the children characterized by having the spirit of cooperation and receptive or hostile seeking dominance.

The third hypothesis stated that attentional bias in children with conduct disorder is more than normal children. The results of this research were examined with regard to large groups of patients who are easily distracted by a neutral stimulus. It seems that selective attention to threat prepares people to experience further distress following the negative events (MacClaude et al., 2000). For example, the primary concern of people with panic disorder is associated with threatening nature of their own inner physical sensitivities.

Arousal of attention to threatening signs is one of the characteristics of children with conduct disorder (American Psychiatric Association, 2013). So, it is expected that they show attentional bias to different types of threatening information (Bradley et al., 1999; cited in Bahrami \& Nikyar, 2005). Bias in the processing of emotional information underlies the anxiety disorders and this bias exists in all the stages of information processing, namely attention, interpretation and memory (Matthews \& McLeod, 1994; cited in Ostovar, 2006).

Attentional bias for negative social vocabulary was shown in modified point tracking task in children with conduct disorder (Matthews et al., 1996; cited in Bahrami \& Nikyar, 2005). Thus, empirical evidence indicates that attention in psychological disorders plays a causal role. It is thought that high levels of state and trait anxiety lead individuals to automatic attentional bias towards threatening stimuli.

If we assume that factors such as the length of the written words or their difficulty have a role in creating this phenomenon (interference effect), we should expect a similar pattern of slow performance in both groups (i.e. normal group and group of patients with social phobia with different religious orientations), which suggests the involvement of physical and social threat words when determining their colors; especially that these two groups were matched in terms of some important variables such as gender, education and age. Data indicated that only the group of patients with social phobia (with extrinsic religious orientation) showed such pattern of interference effects. Therefore, this interference effect cannot be attributed to factors such as the length of words or their difficulty or possibly other similar factors; but it can be said that religious orientations are effective in this regard.

If we attribute the involvement of physical and social threat words in performing color determination only to the level of individuals' anxiety and depression rather than their intrinsic and extrinsic religious orientations, then we should expect that these patients show slow performance in relation to other symptoms presented in the test (positive symptoms and other signs) whereas we did not observe such a phenomenon in the research findings. Hence, it can be said that if the level of anxiety and depression of individuals has played a role in their slow performance against the signs of physical and social threat, this has been coupled with some other factors. These results are congruent with the studies by Davidson (2000) and Turner and Beidel (2007).

Besides, it can be stated that existence of memory structures (schemas) in terms of their appropriateness to signs of physical and social threat leads to attentional bias in patients with social phobia disorder (with extrinsic religious orientation) towards these signs and then, further processing is performed on these signs. Since this process takes time and power, it results in slow performance of the individuals with extrinsic religious orientation (determining the color of signs). This explanation is consistent with cognitive formulations in recent years about anxiety disorders indicating that patients suffering from anxiety have structures (schemas) in their long-term memory, which are associated with threat and danger (Beck \& Emery, 2005).

The simplest explanation is that we accept that the processing of threat signs has been performed automatically or semi-attentionally (pre-attentive). In this case, this view is consistent with those previous results which have shown that the processing of threat signs in anxiety disorders is performed automatically or semi-attentionally (Matthews, 1999). But considering the test method used in this study (i.e. using Stroop test pattern), in which signs of stimuli were made available collectively (subtest) to the participants, judgment about the automaticity of signs processing is very difficult and the detailed analysis of this phenomenon requires the use of more precise methodology (e.g., use oftachistoscope which is able to make the signs available individually to the subjects.

Another explanation in relation to the recent finding is the issue that is mentioned by Holender (1986), stating that 
participants may temporarily be aware of the signs' semantic content but forget it quickly during the test (Matthews, 1999). And finally, the last explanation is that the phenomenon of "cognitive avoidance" might have prevented from remembering the signs that have been more exposed to processing. Phenomenon of "cognitive avoidance" indicates that anxious people direct their attention towards those natural stimuli which are related to emotional concerns. Nevertheless, this does not necessarily mean higher intakes regarding these stimuli.

Another finding of the research showed that people with moderate to severe depression spend more time processing the signs, compared to individuals with mild depression. This difference is not significant regarding anxiety and variables such as education and age of participants.

Beck et al. (2004) believe that these patients have a variety of negative cognitive schemas. These negative depressive schemas remain hidden unless the person is faced with stressful stimuli related to the schema. These schemas are activated by the occurrence of stressful stimuli. As previously stated, it seems that depressed people participate with difficulty in encounters and processing the data obtained from experience.

It should be noted that in this study, attempts have been made to examine those variables that may be more effective in the process of attentional bias. Thus, it is recommended that other demographic variables and anxiety disorders be considered in future studies.

According to the results of the research, the possible reason for self-focused attention in children with conduct disorder as compared with normal children is their concern about social encounters which make them pay more attention to inner thoughts and attitudes.

Regarding the second hypothesis, external-focused attention in children with conduct disorder is mostly due to their obsession in social interactions and that they look at themselves from the perspective of other people and humiliate themselves. Also, these patients attribute any problem in their relationship to themselves (e.g., taking an examination and paying attention to one's inner aspects and not blaming the external environment); this case showed a significant relationship (Mesh \& Wolf, 1998; cited in Mozaffari \& Forou al-Din, 2010).

\section{References}

EbrahimiMoqaddam, H. (2012). Use of cognitive-behavioral therapy (CBT) in the treatment of anxiety disorders in children. Torbat-eJam: First Research and Therapy Conference of Clinical Psychologists.

Ostovar, S. (2006). Investigating the memory bias (cognitive) in adolescents with psychology phobic disorder, 10 (3): 39.

Branch, R. \& Wilson, R. (2012).Cognitive behavior therapy. Translated by M. QaracheDaqi. Tehran: Avand Danesh Publications.

Blackburn \& Davidson (2005).Cognitive therapy of depression and anxiety. Translated by H. Toozandehjani. Mashhad: Astan Quds Razavi Publications.

Bahrami, F. \& Nikyar, H. (2005).Metacognitive behavioral therapy for bipolar disorders. Isfahan: Mani Publications.

Toozandehjani, H. (1996). International classification of mental and behavioral disorders. Clinical descriptions and diagnostic guidelines, World Health Organization (ICD-IO). Mashhad: Marandiz Publishing.

Jalali, M. (1997).Investigating the effect of methods of model-taking teaching and practice and relaxation in the treatment of nonassertive behaviors and training the assertive behaviors. PhD thesis, Tarbiat Modares University.

Haqiqi, M. (2012).Effectiveness of retraining attention in reducing the attentional bias toward rejection insocial-oriented people with depressed mood. Torbat-e-Jam: First Research and Therapy Conference ofClinical Psychologists.

Khadivizand, M. (2006).Journal of Mental Health News. Journal of Knowledge, Research and Education, $11(41,45)$.

Rasti, A. (2009). Implicit memory bias toward negative emotional information processing in patients with generalized anxiety disorder, major depression and normal individuals. Department of Clinical Psychology, University of Shiraz, 8, (3): 25-32.

Komijani, M. (2003).Syndrome and etiology of conduct disorder. Journal of Special Education, No. 24 \& 25.

Kaplan, H. \& Sadok, B. (1991).Psychiatry Summary. Translated by N. Pour Afkari. Tabriz: Zoqi Publications.

Kaplan, H.\& Sadok, B. (1991).Diagnostic and Statistical Manual of Mental and Behavioral Disorders (DSM-V).Translated by Y. SeyyedMohammadi. Tehran: Publications.

Mobini, S. (1993). Examining the role of focus of attention in memory bias in depressed patients. Vol. 2, No. 1 \& 2.

Mojtahedi, et al. (1996).Psychiatry Summary. First Edition. Tehran: Arjmand Publications.

Mesh, E. \& Wolf, D. (2010).Child Psychopathology. Translated by M. Mozaffari \& A. Forou al-Din. Tehran: Roshd Publications.

Nourbala, A., Naeiniyan, M., Maddahi, M., Allahyari, A, \& Biyabangard, E. (2000). Diagnostic and Statistical Manual of Mental Disorders, Second Edition (Vol. I). Tehran: Shahed University Publications. (1998).

Houghton, K. \& Salkovix, C. (1997).Cognitive behavioral therapy. Translated by H. Qasemzadeh. First Edition. Tehran: Arjmand Publications. 